\title{
Do Slower Life History Strategies Reduce Sociodemographic Sex Differences?
}

\author{
Cindy Elizabeth Chavarria Minera \\ Aurelio José Figueredo \\ Laura Gail Lunsford \\ University of Arizona
}

\begin{abstract}
This study examines the relations between sociodemographic sex differences and life history strategies in the populations of Mexican States. Sex differences in anatomy and behavior was measured with traits such as educational achievement, mortality, and morbidity. The data were obtained from the Instituto Nacional de Estadística y Geografia (INEGI) and sampled from thirty-one Mexican states and the Federal District $(\mathrm{N}=32)$. An extension analysis was performed selecting only the sex ratio variables that had a correlation with the slow Life History factor greater than or equal to an absolute value of .25. A unit-weighted sex ratio factor was created using these variables. Across 32 Mexican states, the correlation between latent slow life history and sex ratio was .57 ( $p<$ .05). These results are consistent with our hypothesis that slower life histories favor reduced sexual dimorphism in physiology and behavior among human subnational populations. The results of the study further understanding of variations in population sex differences, male-biased behaviors toward sexual equality, and the differences among subnational (regional) populations within the United States of Mexico.
\end{abstract}

Keywords: Life history theory, Mexican states, sexual dimorphism, sex differences

Some societies have greater levels of equality between the sexes compared to other societies. Life History (LH) theory may be a useful perspective for examining and understanding the causes and effects of sex differences among populations. LH Theory provides insight into human behavior from an evolutionary perspective, by providing potential explanations about how people differentially allocate resources, such as time and energy, in response to the varying demands of their environments (Figueredo, Vásquez, Brumbach, Schneider, Sefcek, \& et all, 2006; Del Giudice, Angeleri, \& Manera, 2009).; Cabeza de Baca \& Figueredo, 2014). According to Figueredo, Vásquez, Hagenah Brumbach, and Schneider (2012), LH theory provides insights into the interrelated clusters of individual differences that account for an orderly variation in a wide range of social and health related behaviors, personality factors, and overall health factors. Over evolutionary time, different life history strategies may contribute to the relative magnitudes of sex differences on physical characteristics, and not just behavioral ones. We therefore think that LH strategies might explain some of the observed variation in sex differences among human populations.

The present study builds on the work of Cabeza De Baca and Figueredo 
(2014) as well as Trivers and Willard (1973). Cabeza De Baca and Figueredo (2014) found that a combination of greater population densities and higher levels of human capital were associated with slower life histories. Trivers and Willard (1973) predicted that natural selection leans towards a sex ratio favoring higher investment in boys than in girls in polygynous species when resources are abundant. It is less clear what the relationship between life histories of the slower average LH population and sexual dimorphism is.

According to Olderbak \& Figueredo (2010), slower LH strategists engage in lower levels of sexually aggressive behavior. This is because slower LH strategists tend to invest more time and resources into fewer sexual partners when compared to fast LH strategists who have scarcer resources and many sexual partners. If true, this could account for the differences in sexual dimorphism in slower LH populations.

We hypothesize that human populations with slower average $\mathrm{LH}$ strategies will exhibit less sexually dimorphic behaviors. This prediction derives from the fact that slow LH strategists engage in higher levels of parental effort than fast LH strategists; in so doing, the male is often recruited to assist the female with parental care activities, thus reducing the key difference between the typical mammalian male and female sexual roles. As the two sexes converge upon similar socioecological niches, systematic differences between them are selected against (Atkinson, L. 2012; Bugental, Corpuz, \& Beaulieu, 2014; Cabeza de Baca, SotomayorPeterson, Smith-Castro, \& Figueredo, 2013). An extreme example of the outcome of this process can be found in many species of monogamous Psittacine parrots, in which the males and females of the species are virtually indistinguishable in morphology and behavior. Therefore, slower life histories are theoretically expected to be associated with reduced sexual dimorphism in many socially relevant behaviors across human populations.

\section{Life History Theory}

LH theory explains how organisms distribute time and bioenergetic resources among different facets of somatic development, health maintenance, and reproductive effort to increase their overall fitness (Del Giudice \& Belsky, 2010; Figueredo, Vásquez, Hagenah Brumbach, \& Schneider, 2012). MacArthur's and Wilson's (1967) work stimulated new research in comparative LH by focusing attention on how ecological factors between-species shape the resource allocation of the different species. Traits that confer higher fitness in one environment may not be as advantageous in another environment (Reznick et al., 2002). MacArthur and Wilson (1967) explained this phenomenon by describing the variation in organism's LH as the result of density-dependent selection. Density- 


\section{LIFE HISTORY AND SEX DIFFERENCES}

dependent selection occurs when the genetic makeup of a population responds to changes in the total population size (Lande, Engen, \& Sæther, 2009). Pianka expanded MacArthur's and Wilson's (1967) work by describing how there were correlated clusters of LH Traits, called LH strategies. One latent dimension of LH, called LH speed, ranged from what Pianka called $r$-selected (fast LH) to $K$-selected (slow LH) strategies. For example, Pianka predicted how Life History strategies would change in response to the demands of high population growth rates versus high population densities (Pianka,1970; Reznick et al., 2002). The theory of $r$ and $K$-selection was prominent to the field of Life History evolution because it satisfied the desire to enumerate laws of nature (Reznick et al., 2002). Ellis, Figueredo, Brumbach, \& Schlomer, (2009) point out that the progress made within the past two decades in LH theory has greatly extended and built upon these early models, but has not completely overturned the originally hypothesized selective efficacy of population density as one ultimate cause of LH evolution among the others.

More recently, the application of life history theory toward humans has been utilized to understand various psychosocial phenomenon and individual differences. For instance, LH theory has been utilized to understand relationship satisfaction (Olderbak \& Figueredo, 2010), Cognitive Abilities (Cabeza de Baca \& Figueredo 2014), and individual differences in sexually coercive tendencies (Gladden, Sisco, and Figueredo, 2008). In the Ecological Psychology of Gibson (1979), the challenges and the opportunities are called affordances. Affordances are apparent opportunities that are perceptible for action. Such opportunities are specified by ecological material of the environment (Gibson, 1979). This is important due to the differences in choices between that a SL or FL history recipient would make. Such choices are influenced by their environmental circumstances, including both the challenges and opportunities (Affordances) offered by these circumstances (Kruger, Nedelec, Reischl, \& Zimmerman, 2015; Figueredo, Cabeza de Baca, \& Woodly, 2013).

$K$-selected (slow) and $r$-selected (fast) $\mathrm{LH}$ strategies demonstrate opposite poles of a continuous scale (Manson, 2015; Figueredo et al., 2013). A good way to understand this is to think of the scale with one end of it being faster LH, which is naturally selected by an environment that is rapidly changing and volatile. On the other end of the scale is slower $\mathrm{LH}$, which is naturally selected by an environment that is safe and predictable. Fast LH strategists try to maximize reproductive rates compared to slow LH strategists who try to maximize longevity of self and offspring. Those individuals trying to maximize their proliferation are doing this to buffer against being in an environment that is unpredictable. Those trying to enhance longevity and parenting are doing so to enhance their offspring's quality and competitiveness in stable and saturated environments. 
Following LH theory, $r$-strategists evolve and develop under unpredictable and unstable environments, leading to a strategy that places emphasizes on the production of new individuals (Figueredo et al., 2012; Ellis et al, 2009). In other words, $r$-strategists focus on offspring quantity. On the other hand, $K$-strategists evolve and develop under stable and predictable environments; because of this the $K$-strategists place focus on the survival of existing individuals, whether self, offspring, or genetic relatives (Manson, 2015; Del Giudice, 2009).

LH strategists divide their resources among two areas, called fitness components: somatic effort and reproductive effort (Figueredo, Cabeza de Baca, \& Woodley, 2013; Figueredo, Vásquez, Brumbach, Schneider, Sefcek, Tal, \& et. all, 2006; Störmer, \& Lummaa, 2014; Sefcek, Black, \& Wolf, 2015). Somatic effort is defined as the investments in the organism's own development and maintenance (Störmer, \& Lummaa, 2014; Sefcek, Black, \& Wolf, 2015; ). Reproductive effort includes resources an organism allocates to genetic replication via the procreation of new organisms. Reproductive effort can be further divided into two areas: mating effort and parental/nepotistic effort (Olderbak \& Figueredo, 2010). Accordingly, $r$-strategist humans evolve in harsh and unpredictable environments and are less likely to devote resources towards somatic effort, because allocating resources towards somatic effort is unfeasible due to the high degrees of extrinsic (meaning uncontrollable) morbidity and mortality in such environments. Parental/nepotistic effort is the allocation of resources towards offspring and genetic relatives (Olderbak \& Figueredo, 2010). For the same reason, $r$-strategists are also less likely to place much less care into parental/nepotistic effort; $r$-strategists have a higher likelihood of allocating more resourses towards mating effort, which are resources devoted towards attaining and/or retaining sexual partners, with the final function of producing offspring (Olderbak \& Figueredo, 2010). In contrast, $K$-strategists evolve and develop in stable environments; they are more likely to place emphasis on somatic and parental/nepotistic effort. Both strategies may be equally effective in different environments, according to the discrepant demands of those environments.

\section{What do LH Strategies Have to do with Sex Differences?}

Slower LH strategists invest their resources in long-term relationships and having fewer sexual partners over the course of their lifetime. This may be one reason why slower LH strategists engage in less sexual aggression (Mathes \& Macomb, 2011; Olderbak \& Figueredo 2010). As sexual aggression is presumably something not conducive to the maintenance of a long-term pair band, there would be less of a need for differences between males and females. Slow LH strategists generally have 


\section{LIFE HISTORY AND SEX DIFFERENCES}

history of having fewer sexual partners and thus having a lower need for aggression when competing for mates.

In the present study, we therefore propose that there should be lower degrees of sexual dimorphism in human populations characterized by slower LH strategies. Thus, an examination of national data sets may enable us to test whether LH strategies influence regional sex differences in areas like educational achievement, mortality, and morbidity.

\section{Methods}

We gathered statistics on thirty-one Mexican states and the Federal District $(\mathrm{N}=32)$ from multiple national data sources such as Instituto Nacional de Estadística y Geografía (INEGI). All statistical analyses were conducted using UniMult (version 2), an online Java-based statistical program (Gorsuch, 2015).

We constructed two latent common factors, a Slow Life History Factor and a sex ratio Factor. The former was based on previously published results (Cabeza de Baca \& Figueredo, 2014), and the latter was derived from the results of an extension analysis, as described below. We then tested the relationship between the two factors to test our main study hypothesis that slower life history should be associated with lesser sexual dimorphism, as indicated by less biased sex ratios in various sociodemographic and biomedical outcomes.

\section{Slow Life History Factor}

The Slow Life History Factor (SLHF), also known as K-Factor, was calculated from the same specifications as the unit-weighted factor constructed by Cabeza de Baca \& Figueredo (2014) for state-level Mexican data. They used nine indicators of slow Life History: life expectancy (INEGI, 2013); adiposity rates, as defined by the property of containing high proportions of body fat (Jalisco, Consejo Estatal de Población, 2010); male-biased sex ratios; marriage rates; infant mortality rates; fertility rates; AIDs rates; infection rates; organized crime rates; and homicide rates (2006-2013; per 100,000) (INEGI, 2013). To correct for the influence of high level of homicides produced by the ongoing armed conflict among rival drug cartels in Mexico, the rates of homicides were averaged from 2006 to 2012 to stabilize the scores (Cabeza de Baca \& Figueredo, 2014). See Table 1 for the factor loadings of these indicators of the SLHF.

\section{Sex Ratio Factor}

The current investigators constructed a sex ratio factor from 15 variables, as described below. The authors first disaggregated by sex, 65 
state-level demographic variables that were sampled (INEGI, 2013). These demographic variables were selected from the categories of health, education, and transportation safety, because of their hypothesized relations to Life History strategy.

Table 1

Factor Structure for Slow Life History Factor (Cabeza de Baca \& Figueredo, 2014)

Indicator variables $\quad$ Factor loadings

\begin{tabular}{lc}
\hline Life expectancy & $.87^{*}$ \\
Fertility rates & $-.47^{*}$ \\
Homicide & $-.50^{*}$ \\
Sex ratio at birth & $.32^{*}$ \\
Infant mortality & $-.76^{*}$ \\
Organized crime & $-.41^{*}$ \\
Marriage rate & $.54^{*}$ \\
Obesity & $.44^{*}$ \\
AIDS & $.23^{*}$ \\
\hline Proportion of variance explained & $.29^{*}$ \\
\hline
\end{tabular}

Note: Factor loadings are factor-indicator correlations.

${ }^{*} p<.05$

Next, sex ratio variables were constructed for all of these male and female frequencies, calculated according to the traditional androcentric formula used in biology, which is as follows below where sex ratio is a ratio of men to women and $\mathrm{n}$ refers to the number of females and males:

Sex ratio $=n$ (males) $/ n$ (females)

An extension analysis was then performed by examining the correlations among all the constructed sex ratio and the unit-weighted SLHF. Unimult 2 automatically performs an extension analysis whenever a factor analysis is run. An extension analysis refers to estimating the relationship of common factors to variables that were not included in the factor analysis (Gorsuch, 1997). The purpose of such an analysis is to examine the correlational structure between a set of core items and a larger set of possibly related items (Gorsuch, 1997a, 1997b); this procedure allows one to determine which other items in the item pool examined correlate most highly with the core items. The items that correlate highly with the core items are therefore candidates to be considered as additional convergent indicators of the common factor being measured by the core 


\section{LIFE HISTORY AND SEX DIFFERENCES}

items. In other words, extension analysis compares the factor(s) created with all variables that were omitted from the factor model to screen those variables for possible future inclusion in the factor model.

In the extension analysis conducted, sex ratio variables were selected for inclusion that had a correlation greater than or equal to an absolute value of .25, anything under $r=.25$ was not selected. We selected .25 as a cutoff for the "hyperplane" loadings as the one-tailed probability of a correlation of that magnitude was not statistically significant for $\mathrm{n}=32$ $(\mathrm{p}=.0838)$, whereas the one-tailed probability of a correlation of .30 was $(\mathrm{p}=.0476)$. A factor analysis was performed for the 15 sex ratio variables, specifying that they should all converge upon a single sex ratio factor. Each of the sex ratio variables were assessed this way with respect to the latent construct. After inspection of the unit-weighted factor loadings (factorvariable correlations), indicators were eliminated if they did not have a correlation greater than or equal to an absolute value of .25.

An expanded unit-weighted sex ratio factor was then constructed from the convergent sex ratio indicators that had factor loadings greater than or equal to an absolute value of .25. Finally, we correlated the sex ratio factor with the SLHF. Thus, the final sex ratio factor was based on 15 sex ratio items.

There were four categories of sex ratio variables (accidents, morbidity, mortality, and education). These categories were chosen based on the public availability of the data as well as our theoretical predictions regarding items that should and should not show sexual dimorphisms. The first set of sex ratio variables was traffic accidents, specifically the driver involved in the accident (INEGI, 2013). DeJoy (1992) found that males and females shared common perceptions with respect to the frequencies of the risky behaviors and their likelihood of causing accidents although males viewed such risky behaviors as less serious.

Case and Paxson (2005) found that there where differences in self assessed health between the two sexes (Case \& Paxson, 2005). These findings led to our selection of the second (morbidity) and the third (mortality) set of categories.

The second set of sex ratio variables (morbidity) consisted of neoplastic tumors, mental disorders, the circulatory system, external causes such as injury, poisoning and other consequences (INEGI, 2013).

The third set of sex ratio variables (mortality) consisted of general viral diseases, malignant tumors in the digestive organs, malignant tumors of the respiratory organs, malignant tumors of other sites that are unspecified, mental and behavioral disorders, hypertensive diseases, ischaemic heart disease, overall abnormalities (congenital malformations, deformations and chromosomal abnormalities) (INEGI, 2010). The final category was selected to determine whether sex differences in education solely followed the same patterns as the first three categories. The fourth 
set of sex ratio variables consisted of high school and vocational education (INEGI, 2005). See Table 2 for the factor loadings of each of these indicators with the sex ratio construct.

\section{Results}

The correlation of Sex Ratio Factor (SRF) and SLHF was $r=.57(90 \%$ C.I.: .27, .77; $F(1,30)=14.63, p=.0006)$. The cluster of sex ratio variables was associated with slower life histories. This result supports our hypothesis that human populations with slower average Life History strategies exhibit lower degrees of sexual dimorphism in behavior. Populations with slower average Life History strategies demonstrate lower ratios of sex differences on outcomes related to educational achievement, mortality, and morbidity to a lower degree. Therefore, slower life histories favor reduced sexual dimorphism in human populations.

Table 2 shows the means of each of these sex ratio variables, indicating whether each demographic category was male-biased $(>1)$ or femalebiased $(<1)$. One may observe that for demographic variables that were initially male-biased (sex ratio $>1$ ), the factor loadings were generally negative, which reduced the amount of male bias, whereas for demographic variables that were initially female-biased (sex ratio $<1$ ), the factor loadings were generally positive, which reduced the amount of female bias. In both cases, then, the effect of this common sex ratio factor was generally to reduce the amount of sexual dimorphism in the direction of greater sexual equality.

Table 2 shows the means of each of these SR variables, indicating whether each demographic category was male-biased $(>1)$ or femalebiased $(<1)$. The correlation of these mean sex ratios with their factor loadings gave us the directions and magnitudes of the influences of the latent common factor upon the indicator sex ratios, which was $r=-.48$ $(\mathrm{p}<.05)$. This statistical procedure is a meta-analytic approach to what has been traditionally called the Method of Correlated Vectors (MCV; Jensen, 1998; Woodley of Menie, Figueredo, Madison, \& Dunkel, 2015) and simply involves correlating one vector of parameter estimates with another: in this case the vector of sex ratios with the vector of corresponding vector of SRF factor loadings for the same indicators, weighted by the number of individual observations on which each parameter estimate is based. This negative correlation between the sex ratios and their factor loadings indicates that for demographic variables that were initially male-biased $(\mathrm{SR}>1)$, the factor loadings were generally negative, which reduced the amount of male bias, whereas for demographic variables that were initially female-biased $(S R<1)$, the factor loadings were generally positive, which reduced the amount of female bias. In both cases, then, the effect of this 
common sex ratio factor was generally to reduce the amount of sexual dimorphism in the direction of greater sexual equality.

Table 2

Factor Structure for Sex Ratio Factor

\begin{tabular}{lcr}
\hline Indicator variables & Mean sex ratio & $\begin{array}{r}\text { Factor } \\
\text { loadings }\end{array}$ \\
\hline Driver sex-ratio & 7.56 & $-.53^{*}$ \\
Neoplastic tumors sex-ratio & 0.36 & $.50^{*}$ \\
Mental disorders sex-ratio & 1.22 & $-.62^{*}$ \\
Circulatory system sex-ratio & 1.03 & $.70^{*}$ \\
External causes sex-ratio & 1.30 & $-.40^{*}$ \\
Viral diseases sex-ratio & 2.65 & $.34^{*}$ \\
Digestive tumors sex-ratio & 1.07 & $.70^{*}$ \\
Respiratory tumors sex-ratio & 2.24 & $.60^{*}$ \\
Unspecified tumors sex-ratio & 1.11 & $.59^{*}$ \\
Mental/behavioral disorders sex-ratio & 3.16 & $.46^{*}$ \\
Hypertensive diseases sex-ratio & 0.82 & $.47^{*}$ \\
Ischemic heart disease sex-ratio & 1.39 & $.82^{*}$ \\
Abnormalities sex-ratio & 1.13 & $.32^{*}$ \\
High school sex-ratio & 1.08 & $.65^{*}$ \\
Vocational education sex-ratio & 1.10 & $.66^{*}$ \\
\hline Proportion of variance explained & & $.33^{*}$ \\
\hline
\end{tabular}

Note: Factor loadings are factor-indicator correlations.

${ }^{*} p<.05$

\section{Discussion}

The purpose of the present study was to determine if LH theory might explain sex differences in human subnational populations. We examined the relationships between state-level LH strategies and sexually dimorphic traits in Mexico. Our study makes two contributions to the literature.

Our study suggests that life history theory can help us to understand variations in population-level sex differences. The study produced evidence that LH strategy and sexual dimorphism were related at the subnational level among the States of Mexico. Such findings may also help explain why some populations have greater levels of sexual equality as compared with other populations and explain the sex differences in health. Further, these findings may assist with the further understanding of sex differences within humans and how some populations have a lower degree of sexual dimorphism compared to others. The investigation may show that, with slower life histories, some male-biased behaviors move toward sexual equality reversing any initial bias that the variable might have had, as indicated by the negative correlation among the sex ratios themselves 
and their corresponding factor loadings. Thus, a high factor loading (which represents the direct effect of SRF, and thus the indirect effect of SLHF, upon each indicator) is going to be in the opposite direction to the sex ratio, moving towards being less biased. For example, the sex ratio for the driver variable, which is the person who was responsible for the accident, has a mean of 7.56, which (>1) makes it heavily male-biased; but due to the effect of the SRF (a factor loading of $r=-.53$ ), it becomes more female-biased for slower Life History populations, albeit indirectly, but these results it could suggest that proportionally more of our women than men are dying in car accidents or that there are differences in male and female deaths. For example, female deaths in car accidents are remaining constant and there is a decreased difference in male deaths in slower Life History populations. The same can be said for the differences in the sex ratio for hypertensive diseases. For hypertensive disease variable it was slightly female-biased (having a mean of .82); but due to the effect of the SRF (a factor loading of $r=.47$ ), it becomes more male-biased, meaning that more men are diagnosed with hypertensive disease and that the females are remaining constant in slower Life History populations. If the variable is female-biased, the SRF is producing male-biased sex ratios for the respective demographic variables and vice-versa. In both cases, the $\mathrm{SRF}$ is reducing sex bias, driving demographic characteristics towards sexual equality in slower Life History populations. In a minority of cases, such as the relative prevalence of Viral Diseases, slower Life History populations seem to have increased (rather than decreased) sex bias and we are frankly unable to account for these exceptions. Sexual equality has its positive and negative effects, but this study helps to understand the differences among subnational (regional) populations, at least within the United States of Mexico.

Limitations of the Study. One limitation of this study was the lack of anthropometric assessments in the data, such as the average weight and height of males and females. This kind of information could have contributed to the further understanding of physical sex differences in size and strength, as has been studies widely in nonhuman primates. There was a lot of additional information of this kind that could have aided the investigation, but it was not disaggregated by sex in the databases that were used, leading to that resource not being suitable for this type of research.

Future Research. There are three implications for future research. First, researchers may cross-validate our theory cross-culturally by determining if these findings can be applied to other societies around the world, by comparing the differences between societies that have various different populations within the different regions of one country. Second, it would be very interesting to see if there are systematic differences between members of the same sex (polymorphism) within different 


\section{LIFE HISTORY AND SEX DIFFERENCES}

societies, as well as whether the relative degrees of polymorphism can be predicted from the dominant life history strategy of each subnational region.

Author note: Corresponding author: Cindy Elizabeth Chavarria Minera, email: Chavarriaminera@email.arizona.edu. This research was funded by The Undergraduate Research Opportunities Consortium (UROC-PREP). The Authors would also like to thank Tomás Cabeza de Baca for his support and suggestions on earlier drafts of this manuscript.

\section{References}

Atkinson, L. (2012). Strategic decisions: Life history, interpersonal relations, intergenerational neurobiology, and ethics in parenting and development. Parenting: Science and Practice, 12, 185-191.

Bugental, D. B., Corpuz, R., \& Beaulieu, D. A. (2014). In J. E. Grusec \& P. D. Hastings (Eds.), An evolutionary approach to socialization. Handbook of Socialization: Theory and Research, New York: Guilford Press.

Figueredo, A. J., de Baca, T. C., \& Woodley, M. A. (2013). The measurement of human life history strategy. Personality and Individual Differences, 55, 251255.

Figueredo, A. J., Vásquez, G., Brumbach, B. H., Schneider, S. M., Sefcek, J. A., Tal, I. R., ... \& Jacobs, W. J. (2006). Consilience and life history theory: From genes to brain to reproductive strategy. Developmental Review, 26, 243-275.

Cabeza de Baca, T., \& Figueredo, A. J (2014). The cognitive ecology of Mexico: climatic and socio-cultural effects on life history strategies and cognitive abilities. Intelligence, 47, 63-71.

Cabeza de Baca, T., Sotomayor-Peterson, M., Smith-Castro, V., \& Figueredo, A. J. (2014). Contributions of matrilineal and patrilineal kin alloparental effort to the development of life history strategies and patriarchal values: A crosscultural life history approach. Journal of Cross-Cultural Psychology, 45, 534554.

Cabeza De Baca, T., Figueredo, A. J., \& Ellis, B. J. (2012). An evolutionary analysis of variation in parental effort: Determinants and assessment. Parenting, 12, 94-104.

Darwin, C. (1859). On the origin of species by means of natural selection. London: John Murray.

Del Giudice, M., \& Belsky, J. (2010). Sex differences in attachment emerge in middle childhood: An evolutionary hypothesis. Child Development Perspectives, 4, 97-105.

Del Giudice, M. (2009). Sex, attachment, and the development of reproductive strategies. Behavioral and Brain Sciences, 32, 1-21.

Del Giudice, M., Angeleri, R., \& Manera, V. (2009). The juvenile transition: A developmental switch point in human life history. Developmental Review, 29, 1-31. 


\section{CHAVARRIA MINERA, FIGUEREDO, LUNSFORD}

DeJoy, D. M. (1992). An examination of gender differences in traffic accident risk perception. Accident Analysis \& Prevention, 24, 237-246.

Ellis, B. J., Figueredo, A. J., Brumbach, B. H., \& Schlomer, G. L. (2009). Fundamental dimensions of environmental risk. Human Nature, 20, 204268.

Figueredo, A. J., Cabeza de Baca , T., \& Woodly, M. A. (2012). The measurement of human life history strategy. Personality and Individual Differences, 55, 251-255.

Figueredo, A. J., Vásquez, G., Hagenah Brumbach, B., \& Schneider , S. M. (2012). The heritability of life history strategy: The $\mathrm{K}$ factor, covitality, and personality. Biodemography and Social Biology, 51, 121-143.

Figueredo, A. J., Cabeza de Baca, T., \& Woodley, M. A. (2013). The measurement of human life history strategy. Personality and Individual Differences, 55, 251-255.

Gladden, P. R., José, F. A., Andrejzak, D., Jones, D. N., \& Smith-Castro, V. (2013). Reproductive strategy and sexual conflict: Slow life history strategy inhibits negative androcentrism. Journal of Methods and Measurement in the Social Sciences, 4, 48-71.

Gladden, P. R., Sisco, M., \& Figueredo, A. J. (2008). Sexual coercion and life history strategy. Evolution and human behavior, 29, 319-326.

Gorsuch, R. L. (1997a). Exploratory factor analysis: Its role in item analysis. Journal of Personality Assessment, 68, 532-560.

Gorsuch, R. L. (1997b). New procedure for extension analysis in exploratory factor analysis. Educational and Psychological Measurement, 57, 725-740.

Gorsuch, R. L. (2015). Unimult (Version 2) for univariate and multivariate data analysis. Altadena, CA: Unimult. http://www.unimult.com/index.php/es/

INEGI. (2005). Conteo de Población y Vivienda 2005. Retrieved July 3, 2014, from http://www.inegi.org.mx/est/lista_cubos/consulta.aspx?p=pob\&c=2

INEGI. (2010). Mortalida: Defunciones por homicidios. Retrieved June 30, 2014, from Instituto national de estadistica y geographia: http://www.inegi.org.mx/lib/olap/consulta/general_ver4/MDXQueryDatos. asp?c $=28820$

INEGI. (2013). Censo de poblacion y vivienda. Retrieved June 21, 2014, from Instituto Nacional De Estadistica $Y$ Geografia: http://www3.inegi.org.mx/sistemas/Glosario/paginas/Contenido.aspx?ClvGl $\mathrm{o}=$ cpv2010\&nombre $=001 \& \mathrm{c}=27432 \& \mathrm{~s}=\mathrm{est}$

INEGI. (2013). Censo de poblacion y vivienda. Retrieved June 24, 2014, from Instituto Nacinal De Estadistica y Geografia: http://www.inegi.org.mx/est/lista_cubos/consulta.aspx?p=adm\&c=12

Jalisco, Consejo Estatal de Población. (2010). Sobrepeso Y Obesida. Diez problemas de la población de Jalisco: Una perspectiva sociodemográfica, 135.

Jensen, A. R. (1998). The $g$ factor: The science of mental ability. Westport, CT: Westport, CT: Praeger Publishers.

Lande, R., Engen, S., \& Sæther, B.-E. (2009). An evolutionary maximum principle for density-dependent population dynamics in a fluctuating environment. Philosophical Transactions of the Royal Society B: Biological Sciences, 364(1523), 1511-1518. 


\section{LIFE HISTORY AND SEX DIFFERENCES}

MacArthur, R. H., \& Wilson, E. O. (1967). The theory of island biogeography. Princton, NJ: Princeton University Press.

Mathes, E., \& Macomb, I. L. (2011). The effect of individual differences and manipulated life expectancies on the willingness to engage in sexual coercion. Evolutionary Psychology, 9, 588-599.

Manson, J. H. (2015). Life history strategy and the HEXACO personality dimensions. Evolutionary Psychology, 13, 48 - 66. UCLA: 841117. Retrieved from: http://escholarship.org/uc/item/3qp935pj

Olderbak, S. G., \& Figueredo, A. J. (2010). Life history strategy as a longitudinal predictor of relationship satisfaction and dissolution. Personality and Individual Differences, 49, 234-239.

Pianka, E. R. (1970). On r-and K-selection. American Naturalist, 104, 592-597.

Reznick, D., Bryant, M. J., \& Bashey, F. (2002). r-and K-selection revisited: the role of population regulation in life-history evolution. Ecology, 83, 15091520.

Rushton, J. P. (1989). Genetic similarity, human altruism, and group selection. Behavioral and Brain Sciences, 12, 503-518.

Sefcek, J. A., Black, C. J., \& Wolf, P. S. (2015). Evolutionary perspectives of personality. In V. Zeigler-Hill, L. L. M. Welling, \& T. K. Shackelford (Eds.), Evolutionary perspectives on social psychology. New York, NY: Springer.

Störmer, C., \& Lummaa, V. (2014). Increased mortality exposure within the family rather than individual mortality experiences triggers faster life-history strategies in historic human populations. PLoS ONE, 9, 83633.

Trivers, R. L., \& Willard, D. E. (1973). Natural selection of parental ability to vary the sex ratio of offspring. Science, 179(4068), 90-92.

Woodley of Menie, M. A., Figueredo, A. J., Dunkel, C. S., \& Madison, G. (2015). Estimating the strength of genetic selection against heritable $g$ in a sample of 3520 Americans, sourced from MIDUS II. Personality and Individual Differences, 86, 266-270. 